Case Report

\title{
CHRONIC CONSTIPATION IN INFANTS: THINK ABOUT RECTAL DUPLICATION
}

\author{
Ivona Đorđević ${ }^{1,2}$, Anđelka Slavković ${ }^{1,2}$, Zoran Marjanović ${ }^{1}$, Dragoljub Živanović ${ }^{1,2}$, Milan Slavković ${ }^{3}$ \\ ${ }^{1}$ Pediatric Clinic, Clinical Center Niš, Serbia \\ ${ }^{2}$ University of Niš, Faculty of Medicine, Niš, Serbia \\ ${ }^{3}$ University Children's Hospital, Belgrade, Serbia
}

\begin{abstract}
Rectum is the least common site of gastrointestinal duplication. Up to now fewer than 100 cases have been reported in the literature. We present two infants with cystic rectal duplications manifested with chronic constipation as a main clinical symptom. The first patient was a 4-year-old boy who was admitted to emergency department because of chronic constipation unresponsive to fiber supplements and laxatives. Digital rectal exam revealed mass adjacent to posterior rectal wall. Abdominal ultrasound and magnetic resonance imaging confirmed oval, homogenous and hypoechogenic cystic mass ( $87 \times 65 \times 60 \mathrm{~mm}$ in size) behind the rectum. The size and location of the cystic mass was confirmed by magnetic resonance imaging. The second patient was an 11-month-old boy who was hospitalized due to rectal bleeding. He was suffering from chronic constipation over the last five months. Digital rectal exam revealed a mass behind the rectum. Abdominal ultrasound and computed tomography showed unilocular cyst (33X33 $\mathrm{mm}$ in size) in front of the urinary bladder, partly extending into retrorectal space. Both patients were operated on. Postoperative periods were uneventful in both of them. Cystic rectal duplication must be ruled out in all infants with chronic constipation unresponsive to conservative treatment. Different imaging techniques are currently used to determine the precise size and location of duplication. Surgery is the only possible therapy option.
\end{abstract}

Key words: rectal duplication, children, constipation

\section{Introduction}

Duplications of alimentary tract can occur anywhere from mouth to the anus. The reported incidence of these anomalies is 1 in $4500[1,2]$. They vary in size, shape (spherical or tubular), and may communicate with the lumen of gastrointestinal tract [3]. Rectum is the least common site of the duplication $[4,5]$. There are fewer than 100 cases published in literature [6].

Functional constipation is one the most common reasons parents bring their kids to a doctor. If there is no improvement with medications and dietary changes, organic causes of constipation must be considered. A very rare, but potentially serious cause of constipation in infants is rectal duplication. Delayed diagnosis increases the risk of complications. Therefore, high index of suspicion is needed in all cases of constipation, unresponsive to conservative treatment. In differential diagnosis cystic sacrococcygeal teratoma and anterior meningoceles must be taken into account [7].

Correspondence to: Ivona Đorđević, Ph.D

Pediatric Surgery Clinic, Clinical Center Niš

48 Dr/ Zoran Djindjić Blvd, 18000 Niš, Serbia

Phone: +381638122532

E-mail: ivonadj74@gmail.com

Received September $10^{\text {th }}, 2019$, Accepted January $20^{\text {th }}, 2020$

\section{Case reports}

Case report 1. A 4-year-old boy presented to emergency department for constipation, that was treated with fiber supplements and laxatives over the last six months. Rectal examination revealed cystic mass adjacent to posterior rectal wall; no rectal bleeding was confirmed whatsoever.

Complete blood count and biochemical analyses showed no abnormalities. Initial imaging study included ultrasonographic examination that confirmed extensive, oval, homogenous and hypoechogenic mass $(87 \times 65 \times 60$ $\mathrm{mm}$ ) behind the rectum. Magnetic resonance imaging (MRI) confirmed the presence of the cystic mass (Fig. 1). The patient was scheduled for the operative treatment after obtaining written consent from the parents.

We used posterior sagittal approach and revealed the cystic mass presacrally (Figure 2). The mass was completely excised, leaving the small part of the cystic wall in situ, just in the part that shared the wall with the posterior rectum.

The intervention was finished with proper mucosectomy and drainage placing. The postoperative course was uneventful; the drain was removed on the fourth postoperative day. Histopathology exam confirmed duplication cyst with columnar epithelium, mucosal muscularis layer and true rectal mucosa. 


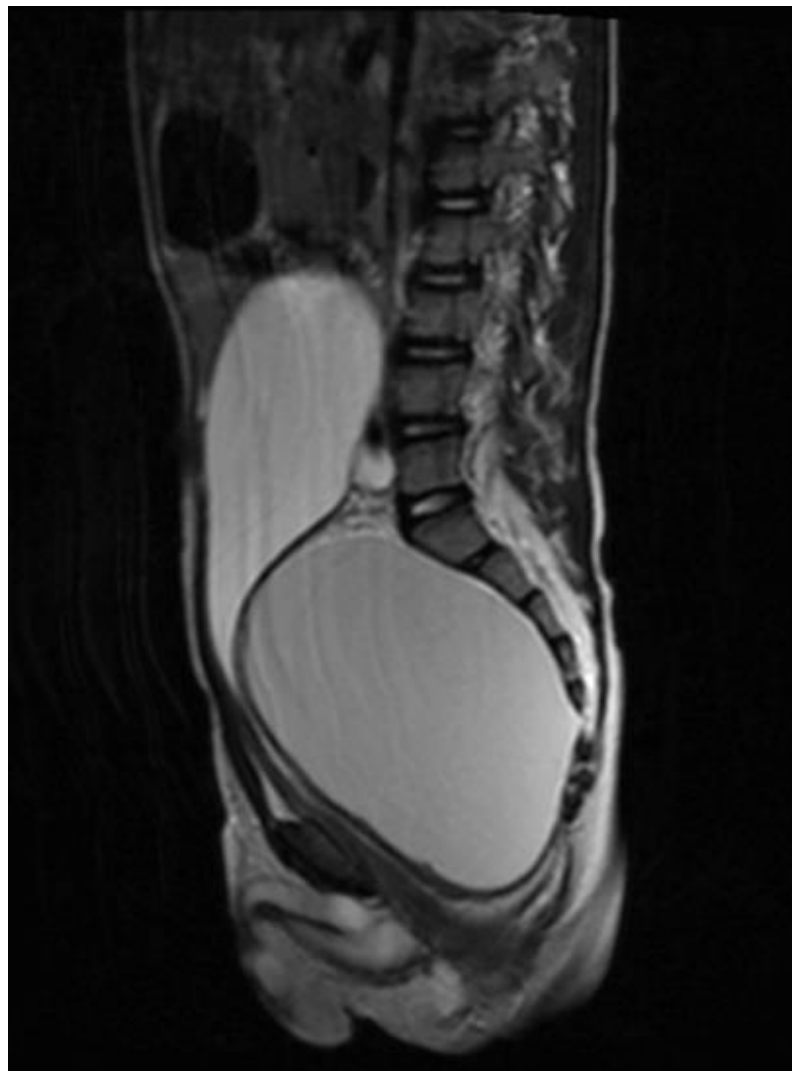

Fig. 1 Large retrorectal cystic mass on sagittal magnetic resonance imaging scan.

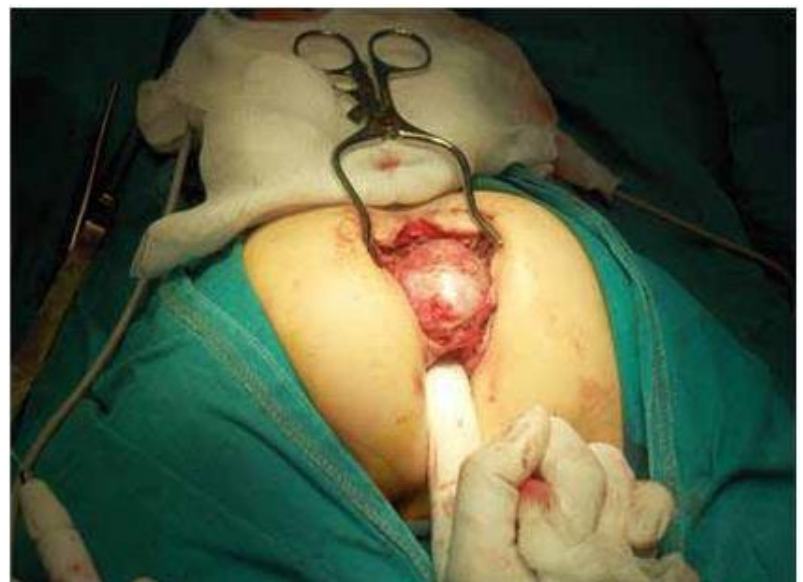

Fig. 2 Operative finding of the retrorectal cystic mass

Case report 2. An 11-month-old male infant was admitted for thorough examination due to rectal bleeding. Patient history revealed chronic constipation over the period of last five months. Digital rectal exam showed cystic mass behind the rectum, that was the most probable cause of the constipation.

Apart from significant anemia (RBC $2.62 \times 10^{12} / \mathrm{L}$, $\mathrm{Hb}-8.2 \mathrm{~g} / \mathrm{L}$ ), all other laboratory analyses were within the reference values. Computed tomography (CT) scan showed well formed, unilocular cystic formation $(33 \times 33$ $\mathrm{mm}$ in size) in front of the urinary bladder, partly extending into retrorectal space (Figure 3 ).

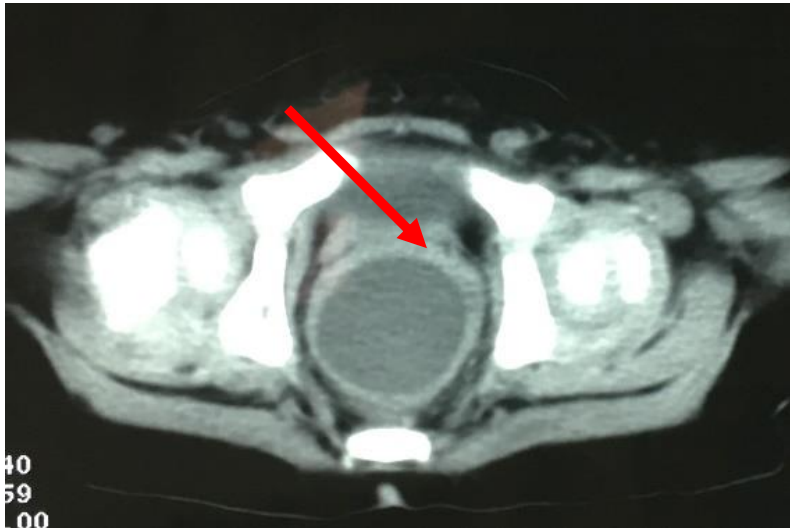

Fig. 3 Rectal duplication on transverse computed tomography scan.

We used posterior sagittal approach for the exposition of the lesion; as no communication with the nearby structures was found, the cyst was been completely enucleated. Having reconstructed the parasagittal muscle complex to preserve the normal sphincter function and continence, the operation was finished with excellent cosmetic result (Figure 4). The postoperative course was uneventful. Histopathology exam proved rectal mucosal lining within the cyst, as well as muscle coat of the wall.

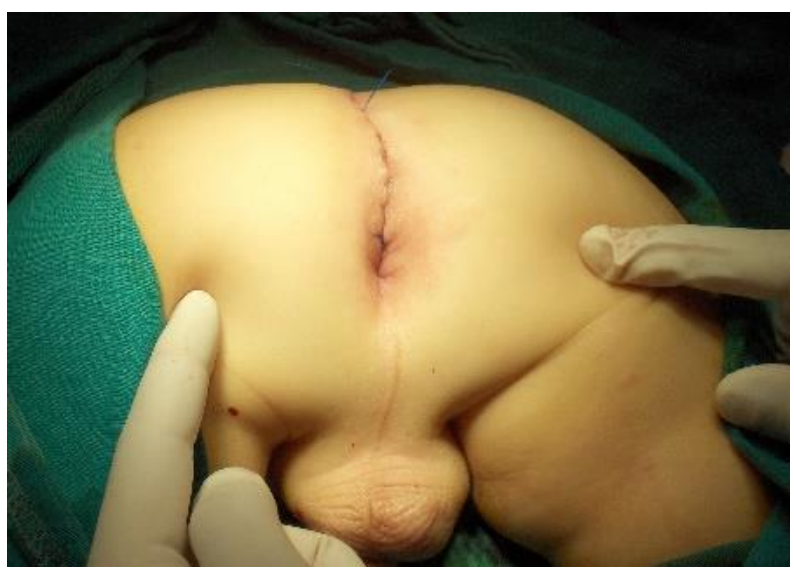

Fig. 4 Excellent cosmetic result after posterior sagittal approach used for the excision of the rectal duplication.

\section{Discussion}

Even though duplication anomalies have been known for a long period of time, Ladd was the first to suggest the term duplication in 1937 [8]. They can be found anywhere along alimentary tract (even thoracoabdominaly), causing variety of symptoms depending on their localisation [9]. They vary in size, can be either tubular or spherical, and may communicate with the intestinal tract [1-3].

Although several theories have been proposed, the true etiology of the duplications remains obscure. Persistence of fetal gut diverticula, defects in fetal gut recanalisation, partial twinning and split notochord theory 
are some of the many proposed [7, 10]. All of them can be applied to some lesions, yet, no uniform theory has been published so far.

Ladd's criteria for characterising the lesion as duplication are still in use [8]. The lesion has well-developed coat of smooth muscle, inner mucosal membrane resembling any portion of the intestinal tract mucosa, and can have an intimate anatomic association with any part of the digestive tube.

Rectal duplications have bimodal presentation and are mostly seen in perinatal period and during early childhood. They can remain asymptomatic throughout the life span or cause complications (constipation, intussusception, rectal bleeding, sepsis and malignant transformation) $[6,11]$ or perirectal sepsis [12]. Malignancy is the most serious complication that is rare in childhood [13]. However, it is not so infrequent in adults (7-18\% cases) [6].

Even though ultrasonography is widely used as the initial imaging study that offers some information about the presence of the mass itself, precise dimensions and

\section{References}

1. Lund DP. Alimentary Tract Duplications. In: Grosfeld JL, O'Neill JA Jr, Fonkalsrud EW, Coran AG, editors. Pediatric Surgery. 6th ed. St. Louis: Mosby; 2006; p 1389-1398.

2. Puligandla PS, Nguyen LT, St-Vil D, Flageole H, Bensoussan AL, Nguyen VH, et al. Gastrointestinal duplications. J Pediatr Surg 2003; $38740-744$.

3. Holcomb III GW, Gheissari A, O'Neill JA Jr, Shorter NA, Bishop HC. Surgical management of alimentary tract duplications. Ann Surg 1989; 209:167-174.

4. Jacquier C, Dobremez E, Piolat C, Dyon JF, Nugues F. Anal canal duplications in infants and children - a series of 6 cases. Eur J Pediatr Surg 2001; 11:1986-1991.

5. Marjanovic Z, Djordjevic I, Slavkovic A, Krstic M. Rectal duplication, rare cause of constipation - case report. Centr Eur J Med 2012; 7(5): 621-623.

6. Harris K, Vellody K. Rectal duplication cyst in a 12 year old female presenting with chronic constipation and rectal bleeding: a case report. Int J Clin Med 2011; 2:5-8.

7. Chandramouli PI, Hossein Mahour G. Duplications of the alimentary tract in infants and children. J Pediatr Surg 1995; 30(9):1267-1270. relation to adjacent organs can be obtained only by MRI which is regarded as imaging modality of choice.

Timely diagnosis of rectal duplication is very important in order to prevent wide array of complications. It must be ruled out in all infants with chronic constipation unresponsive to conservative therapy. Rectal bleeding can also be the first sign of duplications. Conservative therapy is largely without results, and the preferred treatment of gastrointestinal duplications is excision [14].

\section{Conclusion}

In summary, every child with prolonged constipation, unresponsive to conservative treatment, is to be subjected to sonographic examination, in order to exclude the organic cause of the constipation. The widespread utilisation of ultrasonographic examination helps identify the presence of abdominal and pelvic cystic and tubular lesions and demand further diagnostic imaging modalities.

8. Ladd WE. Duplications of the alimentary tract. South Med J 1937; 30:363-366.

9. Bhat NA, Agarwala S, Mitra DK, Bhatnagar V. Duplications of the alimentary tract in children. Trop Gastroenterol 2001; 22:33-35.

10. Knight J, Garvin PJ, Lewis E Jr. Gastric duplication presenting as a double esophagus. J Pediatr Surg 1983; 18:300-301.

11. Boleken ME, Kaya M, Ozardali I, Kanmaz T, Yücesan S. Neonatal cecal cystic duplication mimicking intussusception. Pediatr Int 2006; 48:172-173.

12. Flint R, Strang J, Bissett I, Clark M, Neill M, Parry B. Rectal duplication cyst presenting as perianal sepsis: Report of two cases and review of the literature. Dis Colon Rectum 2004; 47:2208-2210.

13. Kuraoka K, Nakayama H, Kagawa T, Ichikawa T, Yasui W. Adenocarcinoma arising from a gastric duplication cyst with invasion to the stomach: A case report with literature review. J Clin Pathol 2004; 57:428-431.

14.Pal K. A treatise on intestinal duplications. Saudi J Med Sci 2015; 3: $8-15$. 